\title{
A Avaliação de Projetos com Múltiplos Critérios
}

\author{
Luiz Flavio Autran Monteiro Gomes
}

Professor Titular Departamento de Engenharia Industrial - PUC-RJ

Rua Marquês de S. Vicente 225 - sala 954 L - 22453 - Rio de Janeiro/RJ

\section{Antonio Marcos Duarte Jr.}

Doutorando do Programa de Estatística e Pesquisa Operacional

Universidade de Princeton

Palavras-chave: Auxílio multicritério à decisão, avaliação de projetos, sistemas de apoio à decisão

Key words: Multicriteria decision aiding, project evaluation, decision supporting systems

\section{RESUMO:}

A AVALIAÇÃO DE PROJETOS COM MÚLTIPLOS CRITÉRIOS: Este trabalho tem o objetivo essencial de mostrar a necessidade da avaliação de projetos com múltiplos critérios na tomada de decisão associada a sistemas complexos. Assim sendo, o trabalho tem início com uma apresentação da necessidade da ótica multicriterial na avaliação de projetos, tecendo comentários úteis sobre a utilização de procedimentos multicriteriais naquela avaliação. Em seguida, o trabalho estabelece uma conexão entre os processos de tomada de decisão e de planejamento de um sistema complexo. Passa-se, então, a uma discussão dos modelos básicos para o planejamento de sistemas complexos, relacionando-os com o uso da ótica multicriterial na avaliação de projetos. O trabalho conclui com uma síntese das principais vantagens e principais problemas relacionados ao emprego de procedimentos multicriteriais na prática do planejamento de sistemas.

\section{ABSTRACT:}

PROJECT EVALUATION WITH MULTIPLE CRITERIA: The essencial objective of this paper is to point out the need for project evaluation with multiple criteria in the practice of complex systems decision making. The paper therefore starts showing how necessary a multiple criteria approach to project evaluation can be. A connection is then established between decision making processes and complex system planning. Basic models for planning complex systems are discussed and linked to the multiple criteria approach to project evaluation. The paper closes with a synthesis of the main advantages and eventual problems related to making use of multiple criteria approaches in the practice of systems planning.

Rec.05/04/91 Rev.22/04/91 Apr.28/05/91 


\section{Necessidade da \\ ótica multicriterial}

Scrá que todosos problemas decisórios na Engenharia de Produção devem ser resolvidos por meio de uma análise profunda $\mathrm{e}$ detalhada de todos os aspectos que porventura a cles se relacionem? A resposta a esta pergunta naturalmente conterá a forma de agir que o profissional interessado deverá utilizar para resolver os problemas decisórios com os quais venha a se deparar. A resposta dependerá, falandocomsimplismo, da natureza do problema sob análise, das pessoas envolvidas na sua resolução, e do tipode relacionamento social que há entreos envolvidos.

Uma primeira constatação que se pode fazer diz respeito à complexidade do mundo como um todo, assim como de qualquer problema particular seu. Quem quer que já tenha se envolvido em um processo de planejamento para um sistema complexo deve ter percebidoque isolar determinado problema do "resto do mundo" é tarefa das mais difíceis. Isto decorre do fa to de que estabelecer exatamente qual parcela deve ser envolvida na resolução do problema e qual não, deve partir de um compromisso entre a profundidadec extensão com que descjamos tratar o problema, e a dificuldade que por fim teremospara a obtenção da solução final (uma constataçãoéque, quanto mais extensoc menos profundo se torna oestudo realizado para resolução de determinado problema, tão mais superficial será sua solução final). Uma outra forma de colocar a questão é dizcr que se deve reprimir o impulso natural de certos profissionais, envolvidos $\mathrm{em}$ algum processo de tomada de decisão, de tudo considerarem para a resolução do problema (dificultando-o por demais), assim comobus- car conferir realismosuficiente à análisc (para que, por simplificá-la demais, não tenhamos ao final uma solução sem qualquer compromisso com a realidade).

Outro fato de extrema importância para a resolução do problema diz respcito a se ter um perfeito conhecimento de todas as principais consequências das várias alternativas consideradas para a resolução do problema. Tanto as consequências imediatas quanto aquelas relacionadas ao longo prazo são suficientemente importantes para serem consideradas.

Sendo mais objetivos, sabemos que, para a efetivaçãodo processodecisório, deverá ser feita uma modelagem que cubra todos os diferentes aspectos que o modelo escolhido necessite. Antes de introduzirmos a ótica multicriterial que utilizaremos aolongo deste trabalho, vejamos uma breve justificativa para a questão de porque adotar a abordagem decisória multicriterial.

Inicialmente devemos concordar que determinada meta deve ser atingida, podendo esta meta ser a priorização das várias alternativas para resolução do problema, ou, por exemplo, a escolha da "melhor alternativa". Sc, para esta segunda meta, não há o que chamaríamos aqui de "alternativa perfeita" (que superaria as demais alternativas sob todos os aspectos considerados na comparação das mesmas) (1), então certamente ainda teríamos um problema a resolver. Este problema poderia ser solucionado se conseguíssemos estruturar o processo de tomada de decisãode forma tal que todas as preferências escondidas das diversas pessoas envolvidas no processodecisóriopudessen ser detalhadamente esmiuçadas, para, entãu, ao final, obtermos uma solução de compromisso que as refletisse da forma mais real pos-

(1) Definições como "melhor alternativa" ou "alternativa perfeita" envolvem naturalmente conceitos importantes e que devem ser definidos, como, por exemplo, em que conjunto de atributos comparar as diversas alternativas até que se escolha a melhor, ou a perfeita. 
sível. Há várias formas de abordarmos o problema da tomada de decisão, sendo que uma que tem recebido particular atenção ultimamente é a de resolução de conflitos (de qualquer forma deixaremos para vê-la melhor mais adiante neste trabalho).

Fixando-nos na questão do plancjamento de sistemas complexos, ć absolutamente imperiosa a utilização de várias medidas na comparação das diversas alternativas consideradas. Uma ótica soba qual devem ser sempre olhados os projetos é a econômica, uma vez que quase sempre existirão restrições orçamentárias a serem impostas a quaisquer das alternativas sob análise. Mais ainda que uma análise puramente econômica, questões relativas à segurança dos futuros usuários das diversas alternativas não podem seresquecidas. Por fim, para nãonos estendermos demais, um outro aspecto, que vem crescendode importância a cada dia que passa, diz respeito à questão ambiental, devendo-se ter o cuidado de incluir na análise todas as possívcis alteraçōes no ecossistema que as alterna tivas possam vir a causar, para então verificar todos os impactos ambientais de cada uma das alternativas.

Alertamos, entretanto, que qualquer um dos procedimentos analíticos para tomada de decisão são instrumentais analíticos para auxiliar na decisãofinal que se tomará, preferencialmente devendoscr utilizados emuma etapa intermediária do processo decisório. Não devem ser vistos como "modelagens simplísticas da realidade", já que são frutos do esforço de pesquisadores no sentido de conferir maior realismo à decisão final. Devemos admitir aqui que eles são a penas passos intermediários na busca do que chamaríamos de "procedimento multicriterial perfeito"(2), mas que retêm como casos particulares quaisquer das análises unicrite- riais que se ralizam comumente (como uma escolha baseada apenas no valor presente líquido de cada projeto alternativo).

Por serem chamados de procedimentos multicriteriais de auxílio à decisão, já percebemos que tais métodos não são ideais para fornecer uma solução final ao problema sob análise, mas sim uma ordenação (ou partição, dependendo do caso) para uma outra análise mais detalhada a ser feita a seguir. Uma boa opção para a plicação destes métodos á na seleção de um subconjunto de al ternativas para solução de um problema, quando há um número muitograndedealternativas a serem consideradas inicialmente, sendo a análise maisdetalhada, caso a caso, nesta fase inicial, inviável. Um exemplo para tornar maisclaro o que dissemos até aqui pode ser : várias estações ferroviárias (mais de 200) são consideradas para fechamento por apresentarem sistematicamente prejuízos à sua controladora, tendo sido cada uma destas estações analisadas rapidamente esegundo aspectos econômicos segundo aspectos sociais. Uma vez sclecionado um subgrupo do conjunto inicial, uma análise mais cuidadosa é levada a efeito para cada alternativa individualmente (o que não era viável de início).

\section{Procedimentos multicriteriais na avaliação de projetos}

Assumiremos que uma decisão tem que ser tomada. As opções são p projetos (ou alternativas, se o leitor preferir) que deverão ser avaliados por um conjunto de c critérios (ou atributos, se o leitor preferir). Cada um dos projetos é avaliado sob a luz de cada um dos critérios, sendo sua medida de desempenho (em geral numérica) dada por ajk $(i=1,2,3, \ldots, p$ e $k=1,2,3, \ldots, c)$, que ć o elemento

(2) Se este existir. 
geral da matriz A, chamada de matriz de avaliação de projetos. A ordenação final das alternativasédependente da comparaçãodas medidas de desempenho dos p projetos em relação a cada um dos critérios. Vejamosagora alguns comentários úteis:

i) a obtenção do conjunto de critérios que serão utilizados na comparação dos projetos éumdos passos iniciais de qualquer procedimento multicriterial. Algumascaracterísticas que deverão ter o conjunto dos critérios sao: relevância, independência e operacionalidade. A forma de escolha, assim como as pessoas envolvidas, influem no conjunto final que se obterá, devendo-se, por exemplo, perceber que, dependendo do poder que tenha determinado decisor, este incluirá o maior número de critérios que jul gue importantes em detrimento da opinião de algum outro decisor com menor poder;

ii) muitos métodosmulticriteriais sãoperfeitamente capazes de serem utilizados mesmo diante de unidades diferentes dos critérios (comounidade monetáriac unidade de volume) nãonecessitandoqualquer transformação para uma mesma unidade;

iii) há a possibilidade de se considerar no problema multicriterial medidas difíceis de serem instituídas, como por exemplo impactos ambientais negativos das diversas alternativas, simplesmente para tal utilizando-se, por exemplo, de uma ordenação dos projetos no que se refere àquele critério (muito embora esta nãoseja a forma ideal de se agir). Assim, por exemplo, dentre cinco critérios utilizados, quatropodem envolver "medidas intangíveis" (segundo terminologia usada por Bell, Keeney \& Raiffa (1977));

iv) o problema da incerteza nas medidas utilizadas pode ser consideradonos procedi- mentos multicriteriais (por exemplo, com a introduçãodoconceitode "fuzzy numbers", conforme introduzido por Lootsma $(1987, a)$;

v) em geral, nãoé comum considerar-se a avaliação ao longo do tempo, mas, sim, em determinado instante particular. Apesar de reconhecermosque esta é uma limitaçãoséria (pois quase sempre há fluxos monetários ao longo do tempo), sempre é possivel utilizar os procedimentos multicriteriais em combinação com algum método que considere o aspecto temporal. Por exemplo, coma formulação de um programa de programação inteira onde as restrições se relacionam com os fluxosdecaixa em cada período de pagamentoe oobjetivoé maximizar a soma dos pesos finaisobtidos para os projetos por algum procedimento multicriterial utilizado em uma etapa anterior (como se fosse um "Knapsack problem"(3) ligeiramẹnte modificado, com restrições para cada período de fluxo de caixa);

vi) invariavelmentc, quando há diferentes grupos de indivíduos envolvidos no processo de planejamento e tomada de decisão em grupo, a escolha de uma alternativa pode, ao beneficiar um grupo, prejudicar outro. Os principais aspectos que cercam este processo decisório no grupo maior, agregado, não podem ser ignorados.

Aforma geral de agirdequalquer procedimento multicriterial é a busca de uma solução (que podeser, por exemplo, uma priorização dos projetos existentes) através de "trade-offs" entre as medidas de desempenho dos diversos projetos em relação aos critérios escolhidos. Pela sua própria natureza, multicriterial, os procedimentos analíticos têm que atuar diante da presença de cirtérios conflitantes, onde a melhora de um critério, para determinado projeto, é feita

(3) Conforme definido nos livros de programação inteira, como em Hu (1970). 
somente com a piora relativamente a outro critério. Percebemos já aqui que encontrar a "melhor alternativa" não é, na verdade, a forma ideal de se definir a busca de uma solução, para um determinadoproblema, por meio de um procedimento multicriterial. A solução finaléobtida comocompromisso dos diversos "trade-offs" intermediários do procedimento, oque indica que, na verdade, tais métodosencontramoquedefiniríamoscomo uma solução de compromisso ao final. $\mathrm{O}$ pontochave, noentanto, édeterminar da forma mais precisa possível qual o real interesse dogrupo a ser servido pelas melhoras que provirão do processo de planejamento.

Pelasdistintas formas de abordagens que já foram empregadas em modelagens multicriteriais, há uma vasta literatura que cobre todas asseguintes principais abordagens, em seguida delineadas (Bell, Keeney \& Raiffa (op.cit)):

i) Análise custo-efetividade.Cada umdos p projetos sob análise são avaliados por diversos índices de custo e diversos índices de benefícios. Uma vez obtidos estes índices, estabelece-se, para cada uma das medidas de benefício, uma cota mínima de satisfação. Agregam-se(4) todos os índices decustos em um único índice. Busca-se, nesse caso, a solução que minimiza oíndice de custo agregado satisfazendo simultaneamente a todas as cotas mínimas de benfícios instituídas. Uma análise detalhada desta abordagem pode ser encontrada em Thomas \& Schofer (1970);

ii) Análise Benefício-custo . Na linha da abordagem anterior, agregam-se agora não só todos os índices de custo em um único índice, mas também, todos os índices de benefício. A escolha da alternativa final é feita combase na razãodoíndice de benefícioagre- gado e do índice de custo agregado(5), sendoque aqueles projetos que apresentaremos maiores valores serão tidos como os melhores. Para uma colocação mais profunda deste problema sugerimos ao leitor interessado reportar-se a Stopher \& Meyburg (1976);

iii) Análise de Decisão. Inicia-se por indicar as consequências e suas probabilidades para cada alternativa. Determina-se a utilidade de cada uma destas consequências (para cada alternativa). Ao final, ordena-se os projetos de acordo com suas utilidades esperadas (quanto maior esta, tanto melhor se considera o projeto). A referência clássica para esta abordagem é Keeney \& Raiffa (1976);

iv) Otimização Matemática. A forma típica deste problema é a de maximização de uma funçãoobjetivo vetorial, ondecada componente podeser vista comoum critério para o qual vale que "quanto mais, melhor" (no casode minimização valeria o oposto, obviamente). Temos uma região onde estãoconfinadas todas as soluções viáveis para o problema (e que pode ser vista como o conjunto dos projetos sob consideração). Aquele projeto que "maximizar" o vetor objetivo é que deverá ser tomado como o melhor, $\mathrm{e}$ assim por diante (a forma de "maximizar" o vetor objetivo mais usual é aquela que busca interativamente explorar a fronteira de eficiências atrás da solução de Pareto). Qualquer livro de programação multi-objetivo cobre esta abordagem;

v) Psicométrica. Busca-se, por esta abordagem, encontrar uma solução que possua a máxima a traçãopara as pessoas envolvidas no processo decisório. Aqui a orientação e motivação é para explicar, entender e predizer a forma de agir de cada decisor, facilitando então a escolha final. Uma boa

(4) De alguma forma, que não nos interessa aqui

(5) Expressos em unidades monetárias. 
referência para esta abordagem é Hogarth (1975);

vi) Econômica. Considera um consumidor que é confrontado com o problema de escolher uma dentre várias cestas quelhe são apresentadas. Este consumidor é o que chamaríamos de "homem econômico ideal" uma vez que age sempre de forma consistente, assim como tem uma preferência transitiva para toda e qualquer "cesta" que lhe é apresentada. Invariavelmente surgedaquio conceitode funçãode utilidade, que vem para facilitar a ordenação das "cestas" (uma exposição bastante rigorosa do ponto de vista matemático sobrea funçãode utilidade pode ser encontrada em Varian (1984)). Um outro conceitoque surgequando há váriaspessoas envolvidas na escolha das alternativaséode função de bem-estar social, fundamental na chamada "Economia do Bem-estar".

Na seção seguinte apresentaremos como o processo de planejamento era conceitualmente visto a té algum tempo atrás, c como a forma de tratá-lo tem evoluido, tendo-se sempreocuidadodechamar a atenção para como se dá o processo decisório para cada uma das modelagens daquele processo.

Tomada dedecisãocplanejamentode sistemas complexos(6)

Estabeleceremos, nesta seçãodo trabalho, uma ligação entre o processo de tomada de decisão, e o processo de planejamento de sistemas. Nosso interesse principal é mostrar como pode o processo decisório influir na etapa de plancjamento, assim como colocar linhas gerais que possam ser seguidas sem maiores problemas, sempre, independentemente da natureza da estrutura decisória adotada no processo de planejamento.
O processo decisório representa um das mais importantes etapas na claboraçãode um eficaz processo de planejamento. $O$ perfeito entendimento do ato de decidir requer por sua vez do planejador um cuidado especial em aspectos ligados principalmenteàs necessidades em si da estrutura decisória adotada. Negligenciar esta ligação pode resultar, dependendo das falhas cometidas, em soluções afastadas dos reais interesses e necessidades de todas as pessoas envolvidas ao longo de todo o processo de plancjamento. Uma primeira abordagem que se utilizou para oprocessode planejamen to de sistemas foi a que ficou conhecida como "modelo racional". Este consistia basicamente de cinco etapas, onde a premissa de uma forma racional de ação (em cada uma das etapas) se constituia na sua espinha dorsal, tudo isto assessorado por uma maciça assistência computacional, matemática e econômica. Estes cinco passos eram:

passo 1: definição das metas a serem atingidas;

passo 2: perfeita identificaçãodos problemas que serão abordados;

passo 3: identificação e geração de todas as alternativas existentes;

passo 4: identificação e geração de todas as consequências das alternativas anteriormente geradas;

passo 5: Seleção final das alternativas tidas como"ótimas".

O interessante é que, na quinta (e última etapa)citada acima, a alternativa recomendada cra aquela que maximizava alguma medida de performance. Fica já cla ro aqui que, independentemente de que críticas possam ser feitas daqui para diante sobre o modelo racional, uma que obrigatoriamente deveser colocadaéa de seobter uma escolha final uni-

(6) Esta seção do trabalho está fortemente calcada no cap.3 de Meyer \& Miller (1984). 
criterial, conforme se acostumou a fazer imediatamente a partir do surgimento desta metodologia.

De forma mais clara, procurando acoplar a modelagem racional à ótica multicriterial, a nossa sugestão se inicia com uma identificação dos desejos do grupo ao qual oprocesso de planejamento de destina, passando-se em seguida à identificação dos problemas e geração de possíveis soluções (que seriam as alternativas a serem consideradas). Faz-se, então, a geração de todas as consequências destasalternativas, atribuindo-se medidasàs possíveis soluções para, então, em último passo, escolher-se a melhor alternativa por um procedimento analítico apropriado.

A modelagem passou, nos anos posteriores ao seu aparecimento, a ser tratada como um sinônimoda metodologia de planejamento. Isto se deu até o surgimento de quatro novos modelos conceituaisde plancjamento: a modelagem da satisfação, a modelagem incrementalista, a modelagem organizacional ea modelagem da barga nha política. Nós a veremos todas adiante. Por enquanto, vejamos alguns motivos que levaram à elaboração das mesmas, e que surgiram basicamente de alguns pontos fracos da modelagem racional.

A grande falha cstá na natureza da abordagem racional, que praticamente eleva os planejadoresà condiçãode "donos da verdade" (7) cuja missão é a de fornecer ao grupo-cliente um sistema mais eficien te possível concentrando para tal sua a tenção basicamente naquelas possíveis soluções cuja aceitação pelo grupoé consensual.
O resultado é, então, um processo extremamente centralizado, dominado por procedimentos tidos pelos planejadores como inquestionáveis, e que desconsidera totalmente qualquer possivel participação ativa do próprio grupo popular (através de representantes e seus sub-grupos diretamente ou indiretamente afetados). Naturalmente, por ter estas características, a modelagem racional quase sempre resulta $\mathrm{cm}$ projetos de grande porte pouco compreensivos para o grande público sob vários aspectos, a té mesmo no que se refere à sua real intenção (se a de resolveros problemas a que sedestinam, ou se para interesses outros) (8).

Mudanças foram então sugeridas em vários pontos da modelagem racional, dentre as quais destacariamos:

a) tornar o processo incremental, ou seja, com tendência a levar a pequenas modificaçóes, em forma serial, onde os problemas são resolvidos não de uma só vcz, mas, sim, em sucessivas ações. O cuidado que se deve ter aqui é o de não fragmentar o processo de plancjamento de forma a se obter ao final ações que, quando materializadas, não nos levem à solução total e completa dos problemas que desejáva mos resolver inicialmente, ou seja, as ações consecutivas têm que ter entre si uma ligação que garanta a perfeita continuidade do que se planejou como um todo;

b) diante, muitas vezes, da impossibilidade de se atingir uma solução ótima, adotar alternativas que tenham umnível mínimo de accitação pelo grupo. Uma opção aqui pode ser, através de um procedimento

(7) Ou talvez, "neutros".

(8) Oque ocorre para sermos mais claros, é que, frequentemente, pouca ou nenhuma influência têm as opiniões do grupo para as pessoas que têm o poder decisório nas mãos, uma vez que, conforme terminologia já u tilizada, eles são tidos pela estrutura decisória como "donos da verdade". 
analítico multicriterial, adotar-se uma solução de compromisso que reflita a melhor ponderação, dentre os interesses em jogo, para as alternativas consideradas. Neste ponto, pela natureza a té mais estável da solução que propiciam,os procedimentos multicriteriais, constituem, definitivamente, uma excelente opção;

c) considerar o processo de planejamento (seguido de decisão) como sendo plu ralístico, ou seja, uma arena onde se tem diversos grupos envolvidos, com seus distintos valores, objetivose interesses necessariamente presentes, criando conflitos, com subsequente formação de conluios, onde a barganha política se encontra obrigatoriamente presente. A ótica multicriterial pode ser usada aqui em duas formas: em procedimentos onde vários decisores já estão incluídos pela própria natureza do método, resultando, então, ao final, uma única solução (sobre estes métodos, oleitor interessado deve reportar-sea Lootsma (op.cit.) e Lootsma $(1987, b)$ ), ou através de procedimentos onde uma solução de compromisso é obtida para cada grupo presente no processo decisório, para sódepois, então, atingir-se uma solução final global.

Dois alertas cabem aqui, no entanto, no que se refere à terceira mudança colocada anteriormente:

i) não se deve fragmentar por demais a responsabilidade influência no que diz respeito ao processo de planejamento uma vez que, isto ocorrendo, a estrutura deste processo pode se tornar ineficaz para satisfazer os reais desejos dos grupos ligados a distintos aspectos em estudo. A argumentação básica para tal é que, pelo esfacelamento da autoridade para estabelecer prioridades, os planos que são adotados se tornam tão gerais (para atender a todos osinteresses conjuntamente) quanto ineficientes (o que passa a ocorrer é que estes planos são desenvolvidos para ofe- recer "algumas coisas a todas as pessoas"). Resulta ao fim então que o planejamento do sitema não se torna uma ferramenta efetiva nodesenvolvimento doambientedomesmo;

ii) não se deve permitir que o processo de planejamento venha a se tornar mais um motivo para disputa entre diferentes grupos interessados não no bem comum, mas, sim, cada um, na conquista de mais espaço político. É claro que a aceitação política de cada uma das possíveis soluções dependerá do grau de satisfação que estas causem em cada um dos grupos ou instituições sokiais envolvidas, assim como, obviamente, da importância (força) política destas. A influência destes grupos vem tornando, nos países democráticos, o processo de planejamento de sistemascomplexos tão técnico quanto político (o que nãoé mau, desde que, repétindo, o bem comum seja o principal objetivo de todos os grupos envolvidos). Pode-se a té mesmo dizer que a aceitação de inovações em planejamento de sistemas nos dias atuais vem cada vez mais dependendo do grau no qual elas são vistas como inconvenientes por organizações poderosas, assim como grupos bem organizados de votantes.

Oprocessode planejamento podeserconsiderado tanto mais próximo doideal quanto mais oportunidades dá aos planejadores de examinar as alternativas consideradas, fornecendo-lhes, para tal, o maior númerode consequências e características destas alternativas. Oideal se constitui, então, cm planejar com os grupos representantes das comunidades atingidas e não simplesmente para o público em geral, como na estrutura do modelo racional já mencionado.

Vejamosagora, em mais detalhes, os quatrooutrosmodelos conceituais dedecisãoque já citamos anteriormente. Deve-se ser cuidadoso ao estabelecer comparações entre estas diferentes modelagens já que, pelas suas própriasnaturezas, elas apresentamalgumas 
diferenças. Por exemplo, enquanto as abordagens racional, da satisfação e incrementalista pressupõem um processodecisório onde umúnicogrupo (ouórgãogovernamental,ou planejador, etc...) decide, as abordagens organizacional e da barganha política foram desenvolvidas para umambienteonde vários grupos estão diretamente envolvidos noprocesso de planejamento. Felizmente existem similaridades (estruturais) também e sãoestas similaridadesque passamosa discutir, sob o ponto de vista de cada uma dasabordagens.

Veremos os cinco modelos sob os seguintes aspectos:

i) forma de ação assumida;

ii) características assumidas pelo processode plancjamento;

iii) implicações no processo de planejamento tanto de i), quanto de ii).

\section{AS MODELAGENSSÃO ENTÃO:}

racional;

i) na forma de planejamento assumida, as alternativas sãoselecionadas para atingiralgum conjuntode metas pré-determinadas, e o objetivo principal é o de maximizar a função de utilidade da comunidade;

ii) a característica mais importante assumida na aplicaçãodeste processoédeque todas as alternativas foram consideradas, assim como todos os critérios que usaremos na busca da "alternativa ótima" foram plenamente compreendidos $\mathbf{e}$ medidos para todas as alternativas;

iii) o processo decisórioem si implica em uma decisão final oriunda de um processo muito bem estruturado.

\section{da satisfação;}

i) sua estruturação mais comum é tal que a primeira alternativa considerada que atinge determinada cota inferior de satisfação (ou aceitação) é a escolhida;

ii) este tipo de modelagem assume que é impossivel a geraçãode todas as alternativas possíveis (ao contrário da racional), sendo tais alternativas propostas sequencialmente, até que a primeira propicie o mínimo nivel de aceitação desejado pelas comunidades envolvidas. Oatodecisório é orientado por uma meta que se adapta a recursos disponíveis, informações disponiveis, etc...;

iii) como principal implicação do processo decisório está o fato de que os planejadores devem identificar e aplicar niveis mínimos de aceitação para a obtenção de uma alternativa viável (ou alternativas viáveis na medida que adotarmos uma variação desta metodologia onde não só a primeira alternativa a satisfazer a condição mínima de aceitação éconsiderada).

\section{incrementalista;}

i) o processo decisório subjacente aqui é tal que se busca decidir em cima das diferenças marginais entre projetos, e suas consequências sobre os parâmetros de julgamento adotados;

ii) as características do processo decisório levam a que apenas um pequeno número de alternativas e suas consequências sejamidentificados, oque significa dizer, ao final, que solução obtida não necessariamente é "ótima", mas, sim, apenas uma passagem transitória, onde os problemas presentes são comumente redefinidos para se ajustarem à nova realidade; 
iii) a principal implicação da modelagem incrementalista de planejamentoéque, pelo fatodas alternativas diferirem apenas de um pouco daquelas já existentes, muito pouca informação é requerida.

\section{organizacional;}

i) é esta a modelagem que assume que o processo de planejamento é intensamente influenciado pela estrutura organizacional e pelos canais de comunicação existentes dentro do grupo (órgão) plancjador;

ii) como características, temos quea ação, no nível mais alto do processo decisório, é vista como o resultado final de sua organização interna. As alternativas são propostas pelas diversas unidades da organização que plancja e decide, devendoentãoos diversos membros proponentes negociarcm entre si para satisfação de scus desejos (ou melhor, para imporem sua forma de percepçãodo problema e sua solução);

iii) a implicação do processoé, basicamente, que os planejadores devem conhecer as metas de todas as unidades envolvidas, de forma que estas informações específicas sejam incorporadas na análise global de plancjamento.

\section{da barganha política;}

i) assume-se, conforme já dissemos, que o processo de planejamento é pluralístico e caracterizado por conflitos e barganha (entre os diversos grupos interessados);

ii) é caracterizado por um grande númerode valores, metas e interesses envolvidos, onde a barganha surge naturalmente como uma forma de resolução dos conflitos (inevitáveis) que surgem. A solução pode ser vista como uma solução de compromisso para os interesses dos diversos grupos, sendo esta obtida não necessariamente pela resolução emsi dos problemas contraditórios, mas, sim, pelo seu adiantamen to para futuras discussões;

iii) a principal implicação aquié que os planejadores devem ser capazes de lidar da forma mais flexível possível com os conflitosque surgementrcos gruposem competição de forma a que uma solução seja obtida com o mínimo de ressentimentos entre os grupos envolvidos.

Mais alguns elementos se fazem presentes em qualquer processo de plancjamento, independentemente de sua natureza. Relembrando, dissemos que a forma de decisão adotada influi diretamente no tipo de planejamen to que se propõe, sendo uma necessidade entãonãosóocompletoentendimento dos clementos que colocamos a seguir, mas também do processo decisório adotado. Os elementos a mais são:

a) Busca do consenso. É aqui que, em essência, surgiu a modelagem da barganha política. Devidoà natural presença de vários grupos no processo de planejamento e a consequente existência de disputas entre estes grupos, a resolução destes conflitos é uma necessidade do processo decisório, resultando, então, ao final, compromissos negociados, produtos finais de um jogo de barganha que se estabcleceu;

b) Desconsideração dos problemas com alto grau de incerteza. Como o processo de planejamento está quase sempre relacionado com o futuro, as decisões tomadas nos dias atuais terãocertamente que lidar com hipóteses sobre o futuro. Já observou-se que em se tratandodesistemas complexos, é comumos plancjadores evitarem alternativas onde a incerteza égrande, resul tando, portanto, que os projetos efetivamente implementados (na 
sua grande maioria) têm um horizonte de vida não muito longo, requerendo em pouco tempo algumas modificações (cis aqui um doselementos quegerou a modelagem incrementalista). Outro fato observado é que o decisor é, com raras exceções, conservador, evitando também a consideração dealternativas onde características de renovação completa de elementos do sistema atualmente existente estejam presentes (podemos dizer neste caso que a incerteza ligada a estas modificações é grande demais para que os decisores as levem cm conta e implementem, principalmente porque seus cargos e reputação de vários anos estão em jogo!);

c) Alocação de recursos. A perfeita alocação, tanto de recursos financeiros quanto organizacionais, é um dos passos fundamentais para o perfeito estabelecimento do processo de planejamento. A restrição orçamentária nos dias atuais vem se tornando cada vez mais e mais uma restrição mortal para o processo de planejamento, principalmente diante da falta de recursos por que atravessa a maioria dos governos (pelo menos para a satiśáação dos descjos básicos da população!). É interessante notar que o conflito entre grupos ressurge aqui com força total pois, diantede scus desejos, os recursos têm de ser remanejados de uns projetos para outros, oque, em geral, causa disputa nosentido de que determinados projetos permaneçam intocados, deacordo com a opinião de grupos particulares;

d) Busca da satisfação. Pelos pontos delicados com os quais lida (variáveis econômicas, sociais e políticas), os problemas tendem a ser extremamente complexos. Aspectos que devem ser somados a estes são os de natureza ambiental (poluição sonora, visual, do ar, ctc...), c que, nas úl timas décadas vêm se tornando mais e mais importantes. A incorporação destes problemas em um processo decisório, simul taneamente, é fundamental. Neste sentido, os procedimentos analíticos multicriteriais (no que se refere à etapa decisória) lidam com estas dificuldades com uma maior transparência.

Independentementeda forma comoabordamoso processo de plancjamentoe decisão sobre sistemas na grande maioria das vezes os quatro elementos vistos acima estão presentes, causando preocupações aos decisores e dificultando o processo decisório em si.

Passando às características que um processo de planejamento deve apresentar, as principais são:

a) permitir a todos os representantes de grupos de interesse um envolvimento efetivono processo, uma visão bastante clara das implicações futuras que as decisões de hoje podem vir a causare, também, quais oportunidades podem se perder com o que se decidir hoje assim como implicações sobre as atitudes c comportamentos destes grupos;

b) ser capaz de estabelecer o processo de plancjamento em qualquer nível (ou escala) deanálise, preferencialmenteaté mesmoevitando projetos de grande porte, onde os objetivos muitas vezes não são tão facilmente identificados e mensurados, dificultando consequentementea previsão mais precisa de suas conseqüências, assim como uma avaliação mais rigorosa das decisões tomadas;

c) manutenção de certa flexibilidade no processo de plancjamento diante da dinâmica de todos os aspectos relacionados ao sistema, possibilitando assim que, diante de alterações doquadrosócio-político-cconômico, o processo não seja em um futuro breve estancado para um futuro reinício;

d) permitir um fluxocontínuo ao longo do tempo do processo, para que não haja qualquer distanciamento entre a implementaçãoe avaliaçãodasalternativas escolhidas, e as necessidades dos grupos envolvidos; 
e) relacionar realisticamente toda a programação adotada e os recursos existentes para implementação destes programas. Uma falha deste ajuste nos dois cronogramas pode causar, em determinado ponto, ou a completa parada do que se planejou, ou, então, um atraso das medidas planejadas (com consequente perda de credibilidade por parte dos planejadores);

f) uma sexta e última característica desejável é a de propiciar oportunidades para o envolvimento público, oque não deixa de ser uma forma de "educação para a democracia". Valem aqui todos os comentários que já fizemos para o envolvimento de grupos diversos no processo de planejamento.

Passandoagora aos passos que devem ser levados em consideração no processo de planejamento do sistema, estes são $\mathrm{cm}$ número de quatro, basicamente. Resumidamente, seriam:

a) Iidentificação e definição do problema. Certamente, estudos de planejamento somente sãolevados a efeitoquando se percebe um distanciamento entre a realidade co que desejaríamos ter. O primeiro passo $\mathrm{em} \mathrm{um}$ processo de planejamento é, entáo, a identificação do problema, que deve ser seguida pela clara definição do mesmo. Este passo (definição) deve ser realizado com extrema habilidade pelos profissionais responsáveis, já que é aqui que devem ser colhidas as primeiras manifestações de todos os grupos a serem envolvidos no futuro processo de planejamento. Outropontoquedeveserconsiderado nas definiçãoéa abrangência desta, uma vez que, por exemplo; nas últimas décadas, conceitos como impactos ambientais, consumoenergéticoeadequada utilizaçãodo solo têm se tornadocada vez mais presentes, tendendo mais ainda, em futuro próximo, a virem se tornar de capital importância para qualquer análise de sistema. Informações sobre osistema atual e sobre a participaçãoe organização para a decisão são de muita importância nesta primcira ctapa;

b) Debate e escolha. Não é, diante da excassez de recursos e prioridades para cada grupo envolvido, surpreendente que a escoIha de qual projeto alternativo se levar a efeito seja feita em meio a um debate (ou, talvez melhor dito, conflito). A barganha política e a busca por consenso são apenas algumas armas que se utiliza nesta fase do processo, mesmo porque, segundo Meyer \& Miller (op.cit.)," a decisão é a escolha entre alternativas". O ambiente onde se desenrola o processo de planejamento é importante já que, por exemplo, uma decisão extremamente influênciada pela coletividade pode ser caracterizada muito mais pelos compromissosentre os envolvidos do que por características de otimalidade no que se refere à resolução dos reais problemas do grupo. Conceitos comoanálise eavaliaçãode pròjetos, identificação de estratégias e princípios de ação viáveis, são os pontos chaves aqui;

c) Implementação. Uma vez escolhidasas alternativas, passamos ao importante passo de implementá-las. A grande maioria das pessoas envolvidas nas duas primeiras etapassaem, dando seuslugaresaos técnicos, que se encarregarãode levar a efeitoas idéias até então discutidase aprovadas. Nesta fase, para a implementação edesenvolvimento do projeto, é importantíssimo que o cronograma da "obra" e dos recursos financeiros e organizacionais disponíveis estcjam em perfeita sintonia, já que o cumprimento dos objetivos finais estabelecidos é extremamente depenente desta harmonia;

d) Avaliação e acompanhamento. Como nem sempre o que se planejou se comporta exatamente conforme o desejado quando implementado, um acompanhamento de cada estágio da implementação permitirá aos planejadores uma avaliação de até que ponto o proposto surtiu o efeito desejado ou não. 
O monitoramento, então, do processo de implementação é fundamental para a correção de quaisquer distorções que possam ocorrer. Aqui, nesta etapa, é que toda a flexibilidade do planejamento feitoé posta a prova, já que mecanismos de "feedback" terão sua eficiência comprovada ou não, dependentemente desta.

\section{Síntese das vantagens e problemas relacionados com o emprego de procedimentos multicriteriais}

Uma primeira vantagem da abordagem multicriterial é a possibilidade de se utilizar tanto dados quantitativos, quanto dados qualitativos. Usualmentedecide-secom base em medidas monetárias, como por exemplo valor presente líquido, custo total, etc... Também com base cm outras medidas facilmente quantificávcis, como, por exemplo, no caso de um estudo para a extensão de um sistema de metrô a outras localidades, número de pessoas que serão servidas pelas novas estações, distâncias das novas estações em relação às já existentes, ctc... Há, no entanto, outras medidas que são bem mais difíceis de sc quantificar, como, por exemplo, ainda no caso da extensão do metrô, o transtorno temporário (durante a construção) que se causa às pessoas que vivem próximas aos canteiros de obras, características do material quedeve ser removido para construção da nova linha (se há formações rochosas no caminho, requerendo até mesmo o uso de explosivos), ctc... Para estas últimas medidas a soluçãoé a utilização de critérios de na tureza qualitativa, onde ums escala de comparação pode ser construída para a atribuição de medidas às al ternativas sob consideração, sendo feita esta atribuição pelo próprio decisor, de acordo com seu julgamento pessoal.
Uma segunda vantagem dos procedimentos multicriteriais estão ligada a uma modelagem do processo decisório bem mais próxima dá realidade doqueos procedimentos decisórios unicriteriais que, predominantemente, são usados nos dias atuais. Aliás, sempre se pode ver qualquer procedimento unicriterial como um caso particular de qualquer dos quatro métodos que apresentaremosadiante, bastando para tal alocar toda a importância do processo decisório a umúnicodos critérios, em particular,eobviamente, aquele que se quer usar para a decisão final.

A terccira vantagem dos procedimentos multicriteriais écertamentea capacidade que os mesmos têm de levar em consideração todos os diferentes aspectos, simultaneamente, que se relacionam aos diferentes critérios escolhidos para a análise. A idéia subjacente aqui é a de se obter uma solução de compromisso final (para os critérios utilizados), mais estável que qualquer outra solução, pela sua própria natureza, eque leve em consideração todos os critérios simultaneamente, assim como suas respectivas importâncias (scgundo o decisor).

No que se refere à natureza dos procedimentos multicriteriais de auxílio à decisão, há basicamente duas catcgorias segundo as quais cles podem ser classificados (Guigou (1977)):

a) Procedimentos declassificaçãode alternativas. Neste caso, a aplicação do método nos leva à obtenção de uma ordenação das alternativas, sugerindo, portanto, ao decisor uma sequência segundo a qual as diferentes alternativas devam ser levdas a efeito;

b) Procedimentos para participação do conjuntodealternativas. Há aqui vários tipos de participação que se pode impor aoconjunto das alternativas, das quais destacaremos três: 
b.1) Escolha única. Onde seleciona-se uma única alternativa dentre todas aquelas consideradas (o que seria equivalente a escolhermos a melhor alternativa);

b.2) Seleção. Particiona-se o conjunto das alternativas em dois: um em que estão todas as alternativas consideradas boas, $\mathrm{e}$ outroondcestãoasalternativas consideradas ruins (e que, portanto, devem ser descartadas do processo decisório);

b.3) Uma partição em várias classes. A resposta final será, por exemplo, uma participação do conjunto das alternativas em três: um conjunto das alterantivas boas, outro das alternativas regulares, e, por fim, o das alternativas ruins.

De uma forma geral, os procedimentosque são classificados comode partição se preocupambasicamenteem eliminarasalternativas ruins, para en tão depois, o decisor selecionálas melhor. Para o caso onde há um número muito grande de alternativas sob consideração, pode ser recomendável inicialmentea utilização de um método que particione o conjunto das alternativas (selecionando as melhores), para, em seguida, efetuar-se uma ordenação (classificação) dentre aquelas alternativas remanescentes (as classificadas como as melhores, ou talvez, "não-ruins").

Sem dúvida alguma, persiste uma descrença por partede planejadores desistemas complexos em relação à adoção de procedimentos multicriteriais como forma de auxílio à decisão. De um modogeral, a principal fonte desta descrença é a alocação de valores numéricosaos julgamentos requeridos por cada método. É importante, no entanto, notar que estes valores surgem de comparações entre projetos, o que é inevitável sempre que uma ordenação destes (projetos) for desejada (9). Oque simplesmente os procedimentos multicriteriais buscam é o estabelecimento de uma forma racional, realista e transparente deagir (utilizando-se, para tanto, de valores numéricos), para a a partir destas comparações (entre projetos e critérios) chegar a uma priorização final dos projetos.

Um ponto que merece particular atenção para futurasanálises é ode procurar otimizar os procedimentosanalíticos multicriteriais já existentes, principalmente noque diz respeito ao processo de atribuiçãode medidas para comparações entre projetos e critérios, tornando-os assim mais confiáveis e flexíveis.

\section{Referências}

-BELL, D.E., Keeney, R.L. \& Raiffa,H. (1977). Conflicting Objectivés and Decisions. John Wiley \& Sons, New Yorkm U.S.A.

- GUIGOU, J.L. (1977). Méthodes Multidimensionelles: analyse des donnés et choix à critéres multiples. Dunod, Paris, France.

-HOGARTH, R. (1975). Cognitive Processes and the assessment of Subjetive Probability Distributions. Journal of the American Statistical Association, 70, 271-289.

-HU, T.C. (1970). Integer Programming and Network Flows. Addison-Wesley Company, Reading, Massachussets, U.S.A.

-KEENEY,R.L. \& Raiffa, R. (1976). Decisions with Multiple Objectives: preferences and values tradeoffs. John Wiley \& Sons, New York, U.S.A.

(9) Ou scja, o que queremos ressaltar é que, mesmo implicitamente, o estabelecimento de comparações subjetivas entre projetos e critérios é uma tarefa da qual nenhum decisor pode se afastar. 
- LOOTSMA, F.A. (1987,a).Numerical Scalling of Human Judgment in PairwiseComparison Methods for Fuzzi Multicriterion Decision Analysis. Delft University of Technology, Report 87-52, The Netherlands.

- LOOTSMA, F.A. (1987,b). Trade-off Analysis and the Resolution of Conflicts. Delft University of Technology, Report 87-86, The Netherlands.

- MEYER, M.D. \& Miller, E.J. (1984). Urban Transportation Planning: a decision-ori- ented approach. MacGraw-Hill, New York, U.S.A.

-STOPHER, P.\& Meyburg, A. (1978). Transportation Systems Evaluation. D.C. Health, Lexington, Massachuts, U.S.A.

- THOMAS, T. \&Schofer,J. (1970).Strategies for the Evaluation of Alternative Transportation Plans. NCHRP, Report 96, Washington, D.C., U.S.A.

- VARIAN, H.R. (1984). Microeconomic Analysis. W.W. Norton \& Company New York, U.S.A. 